\title{
DIÁLOGO ENTRE LA CULTURA PATRIARCAL-ANTROPOCÉNTRICA Y CULTURA MATRÍZTICA-BIOCÉNTRICA EN LOS CONTEXTOS ORGANIZATIVOS
}

\author{
Claudia Liliana Perlo* \\ Universidad Nacional de Rosario, IRICE-CONICET, Argentina \\ perlo@irice-conicet.gov.ar
}

Recibido: 05/07/2019 - Aceptado: 08/10/2019

\begin{abstract}
Resumen
En este trabajo realizamos una revisión dialógica entre la cultura patriarcal-antropocéntrica vigente y la cultura matríztica-biocéntrica emergente. El propósito del mismo es brindar herramientas teórico-metodológicas para comprender y facilitar procesos de cambios transformativos en las organizaciones. En dicha revisión presentamos las principales características de la cultura patriarcalantropocéntrica dominante en nuestra sociedad actual, en tensión con las características de la cultura matríztica-biocéntrica que se encuentra emergiendo en las grietas de la primera. Se trata de un trabajo de revisión teórica, enmarcado en la teoría enraizada (Grounded Theory). Esto significa que dichos desarrollos se han gestado y nutrido en nuestra tarea de campo en el contexto organizativo, donde hemos puesto en juego las perspectivas que aquí desarrollamos. El escrito concluye con la apuesta y propuesta de dar un urgente y decisivo viraje de la cultura humana que posibilite la co-evolución de esta especie y su entorno.
\end{abstract}

Palabras clave: Cultura - Diálogo - Antropocentrismo - Biocentrismo - Organizaciones.

\section{Summary}

In this work we performed a dialogic 10 atriarc between the present patriarchalanthropocentric culture and the emerging matriztic-biocentric culture. It aims to provide theoretical and methodological tools to understand and facilitate transformative changing processes in organisations. In this review we present the main characteristics of the dominant 10 atriarchalanthropocentic culture in our current society, Making a comparision with the characteristics of the culture matriztic-biocentric which is emerging in the cracks of the previous one. It is a theoretical revision work, framed in the Grounded Theory. This means that these developments have been conceived and nurtured in our task of field in the organizational context, where we have brought into play the perspectives developed here. The paper concludes with the bet and proposal for an urgent and decisive turning of human culture that enables the coevolution of this species and its environment.

*Profesora y Licenciada en Ciencias de la Educación. Doctora en Humanidades y Artes con mención en Educación por la Universidad Nacional de Rosario. Investigadora del Consejo Nacional de Investigaciones Científicas y Técnicas (CONICET), desarrolla su actividad en el Instituto Rosario de Investigaciones en Ciencias de la Educación (IRICE), donde coordina el Área de Aprendizaje y Desarrollo Organizacional. 
Keywords: Culture - Dialogue - Anthropocentrism - Biocentrism - Organisations.

\section{Presentación}

El corpus teórico que presentamos en este trabajo constituye el sustento teóricometodológico en el que se basan los procesos de investigación-acción desarrollados en nuestro equipo de investigación, tanto en el contexto educativo, productivo como comunitario. Dicho corpus se fue elaborando a partir del encuentro y articulación entre conceptos teóricos previos y las categorías emergentes en el campo (Groundead Theory, como se cita en Strauss y Corbin, 1994) que pusieron en cuestión las primeras. Esta producción teórica revisa dos perspectivas culturales en tensión en los contextos organizacionales mencionados: la patriarcal-antropocéntrica, vigente y dominante y la matríztica-biocéntrica, emergente entre las grietas de la primera, hacia la cual nos encontramos transitando. Nos referimos a la cultura en tanto sistema de anclaje de la identidad tanto personal como colectiva, en los espacios organizativos que configuramos con nuestro lenguajear (Maturana y Bloch, 2014) y accionar cotidiano.

En primer lugar, realizamos una breve referencia histórica que dará contexto a tres dimensiones (metacategorías): ontológica, ética y epistemológica que posteriormente constituirán el eje de nuestro análisis en cada una de las culturas mencionadas.

En la dimensión ontológica desarrollamos la concepción de ser y realidad, la relación del hombre con la naturaleza y las metáforas dominantes en lo social y específicamente en el contexto organizativo. En la dimensión ética abordaremos la percepción y configuración de la otredad, las emociones y sentimientos en juego, los valores, actitudes, esto es los vínculos prevalecientes, la concepción del poder y las modalidades conversacionales. Por último, en la dimensión epistemológica pondremos el foco en la concepción del conocimiento, los instrumentos de observación, inteligencia y estrategias metodológicas de enseñanza y aprendizaje inscriptas en el currículum.

Finalmente, en las reflexiones finales ponemos en vinculación con este análisis el problema de la violencia que enfrentan las sociedades y consecuentemente las organizaciones actuales, invitando a un urgente y decisivo viraje cultural.

\section{Revisión histórica}

\section{Orígenes de la cultura matríztica}

Gimbutas (1991) realizó investigaciones arqueológicas relevantes que brindan sólidas raíces para comprender los orígenes de la organización humana. Refiere a la civilización europea en la zona del Danubio entre el 6500 y 3500 a.c., la cual constituyó una cultura basada en una sociedad igualitaria no patriarcal; denominada por la autora matrilineal. En esta organización no había superioridad entre el hombre y la mujer. Éstas últimas jugaban un papel esencial en estas sociedades, las madres eran transmisoras de descendencia y herencia. En estos estudios arqueológicos no se encontraron sucesos de guerras u otros signos de violencia. Según Gimbutas (2014) esto contrasta de manera significativa con la cultura indoeuropea-patriarcal estratificada, predominantemente guerrera, avenida entre los años 4500 y 2500 a.c.

Los descubrimientos arqueológicos llevados a cabo durante el siglo XX y sus posteriores desarrollos teóricos (Mellaart 1970; Gimbutas, 1991; Gómez Robledo, 1971; citados por Riane Eisler, 1990) dan cuenta de un pasado histórico que intencionalmente se ha mantenido oculto. Los mismos refieren a un período de nuestra deriva histórica dónde la igualdad no reconocía jerarquías ni privilegios, no había dominio. Según Eisler (1990) a través del arte puede deducirse que el propósito principal de la vida no era saquear y conquistar, sino cultivar la tierra y tomar de ella los recursos necesarios para una vida satisfactoria. Los grupos sociales se organizaban en torno a la prosperidad colectiva y la colaboración. El acento no estaba puesto en arrebatar y destruir sino alimentarse, proveerse y dar. Tampoco existen registros de nombres de personas que se destaquen por sus proezas o hazañas, por lo que se induce que la ambición personal parece haberse desconocido. Según Nicolás Platón en su cuarto libro "La república" "el miedo a la muerte estaba prácticamente obliterado por la omnipresente alegría de vivir" (Gómez Robledo, 1971, p.34). Eisler, en su libro "El cáliz y la Espada" refiere a un modelo gilánico. Gines significa mujer, la letra I (vinculación/solución o análisis) y an, andro (hombre). Esta descripción de un mundo anterior que integraba lo femenino y lo masculino, "gilánico" en términos de Eisler (1990), matriztico según Maturana y Dávila (2007) explica claramente su ocultamiento dentro del posterior orden patriarcal al que evolucionaría la organización humana. Ahora bien, ¿Cómo es que se produjo este cambio de un modelo solidario a uno dominador?

\section{De la cultura matríztica al patriarcado}

Según el registro histórico (Eisler, 1990) aparecieron grupos invasores (hebreos/indoeuropeos/kurdos/semitas/filisteos) provenientes de diferentes partes que introdujeron 
una forma muy diferente de organización social a la que mencionamos antes. "Estos eran pueblos que veneraban el "poder mortífero de la espada" —el poder de quitar la vida antes que darla, que es el poder esencial para establecer e imponer la dominación" (Gimbutas, 1991, p. 107). Se trataba de un sistema social donde el domino masculino y la estructura social jerárquica se constituyeron en la base de sistemas relacionales caracterizados por la obediencia, el castigo, el miedo, la sumisión (hombre dominador). Hombre cazador que competía con los animales, en especial con el lobo (Maturana, 1994).

El fuerte cambio en la evolución cultural reemplazó el valor de la vida por el poder y dominio para quitarla a través de la guerra y la espada. Es así como la concepción de poder ligada a la capacidad creadora femenina de dar, nutrir y sustentar la vida fue suplantada por el concepto de poder como fuerza opresora, capaz de decidir sobre la muerte y la vida de los otros. Aquí los grupos sociales pasan a organizarse en base a nuevas tecnologías basadas en la extracción, destrucción y dominación.

\section{Sustento científico del patriarcado}

Desde el siglo XVII a esta parte, la ciencia ha tomado el liderazgo del desarrollo de las sociedades humanas. Esta forma de producir conocimiento comprometido con el desarrollo tecnológico ha ido gozando progresivamente de una aceptada y popular reputación hasta la actualidad. Su éxito quizás se deba a los logros conseguidos a la hora de dominar la naturaleza y ponerla al servicio del hombre y también al éxito que gestó el mito del racionalismo ilustrado del siglo XVII. Ya en el siglo XIX, esto posibilitó que algo que estuviera "probado científicamente" equivalía a ser "palabra de Dios" y los científicos/ intelectuales, señores de alabanza.

De este modo se estructuró un universo mecanizado, reduccionista, basado en la causalidad lineal y el determinismo. El cuerpo humano fue equiparado a una máquina, desmembrado en partes y con una razón desarticulada de la emoción. Esta cultura continuó exaltando la competencia para la subsistencia, el crecimiento tecnológico y económico como medio para obtener un progreso material ilimitado (Capra, 1999; Llamazares, 2013). El conocimiento se redujo a la ciencia medible y cuantificable. El método científico pronto se erigió como único enfoque válido para llegar al conocimiento. Fue Descartes, quién desarrolló el pensamiento analítico con su método racional y deductivo. Su declaración fundamental, "Pienso, luego existo", dejó definitivamente atrás el mundo matriztico sensible y dio paso al gobierno absoluto del patriarcado racional.

\section{Retorno al origen: el biocentrismo}

Los desarrollos científicos-tecnológicos desplegados durante las primeras décadas del siglo $\mathrm{XX}$ nos muestran que en las grietas de esta maquinaria viene emergiendo una revolución silenciosa y decisiva para el desarrollo humano.

Hoy en el siglo XXI estamos participando de un tiempo de reconfiguración y resignificación del mundo que cohabitamos. En este continuo devenir de transformaciones, estamos inmersos en una profunda revisión ontoespistemológica de la cultura patriarcal-antropocéntrica. Estamos avizorando un nuevo orden caracterizado por el caos, la recursividad, reticularidad, holoarquía y auto-ecorganización. La perspectiva biocéntrica en la que se enmarcan nuestros trabajos, constituye un encuadre referencial relevante que echa luz y facilita el tránsito del mundo racional mecanizado moderno, hacia el retorno espiralado de nuestro origen matriztico de las organizaciones sociales humanas.

El principio biocéntrico encuentra sólidas raíces teóricas que se remontan a los comienzos de siglo XX en el ámbito de la incipiente ecología. Tanto Aldo Leopold (1949) como John Muir (1971) y posteriormente Arne Naess (1985) sostuvieron la tesis de que el ser humano debía comprenderse y comportarse como parte de la naturaleza.

Hacia la década del 70, el antropólogo Toro Araneda (2007), define al principio biocéntrico como "un pensamiento donde el Universo está organizado en función de la vida. (Toro Araneda, 2007, p. 37).

Desde esta perspectiva que pone la vida en el centro, (Leopold, 1949; Muir, 1971; Toro Araneda, 2007; Cavalcante, Wagner, Diógenes, Arraes, 2004) se enfatiza una ética que reconoce que somos naturaleza, hebra afectada y afectante de una trama mayor. El mundo no es una máquina, sino un todo orgánico y viviente, dentro de él las sociedades y organizaciones constituyen redes que configuran una estructura horizontal, donde la solidaridad intra e interespecie emerge casi como la única posibilidad de evolución y desarrollo. Conocer no es un dominio intelectual específico, sino la vida misma (Maturana, Varela, 2003). La cognición como proceso vital incluye pensamiento, percepción, emoción y acción (Damasio, 2005). La perspectiva biocéntrica abona a esta postura (Cavalcante, 2007) entendiendo que los vínculos que entablamos son del orden afectivo, en tanto pertenecemos a una red que nos entrama y en la misma medida que ella nos afecta, la afectamos. 


\section{Diálogo entre la cultura patriarcal-antropocéntrica y cultura matríztica-biocéntrica} A. Ontología

\section{A.1 Ser y Realidad}

Desde la cultura patriarcal-antropocéntrica, el ser se restringe al "ser humano" y tiene primacía por sobre los otros seres vivos. Se encuentra en el centro y cúspide de la pirámide biológica. Como ya hemos revisado en el apartado anterior esta cosmovisión deviene de un largo y continuo proceso de desencantamiento del mundo (Berman, 2001) en el cual se ha producido un progresivo "borramiento" de la visión de la naturaleza (Capra, 1992). Ser (sujeto) y realidad (objeto) son vistos como antagónicos. La realidad es algo "dado" objetiva, determinada e inteligible por igual a todos los seres humanos. También supone un adentro y un afuera que "rodea al ser" a la vez que lo configura como observador de dicha realidad.

Yo no soy mis experiencias y por lo tanto no soy realmente parte del mundo que me rodea. Esta visión del mundo es una sensación de reificación total; todo es un objeto ajeno, distinto y aparte de mí.

Finalmente, yo también soy un objeto, también soy una "cosa" alienada en un mundo de otras cosas...este mundo no lo hago yo y no me siento perteneciente a él. De hecho, lo que siento es un profundo malestar en el alma (Berman, 2001, p. 11)

Desde una cultura matríztica-biocéntrica se sostiene la intuición de que el universo se encuentra organizado en función de la vida. En este sentido el ser humano vive en interdependencia con todo lo creado, en relación homeostática con la naturaleza. En esta cultura yo soy parte del universo como éste es parte de mí y así toda vida tiene equitativa relevancia. Los seres vivos constituyen una unidad indivisa, donde la realidad construida y múltiple es despliegue, flujo complejo y constante de la totalidad cósmica, inasible y parcialmente inteligible, a alguna de sus subtotalidades cognoscentes. No existe un adentro y un afuera, el ser es inmerso en la realidad.

\section{A.2 Relación Hombre-Naturaleza}

En la cultura patriarcal-antropocéntrica se configura una conciencia científica alienada que no guarda conexión con la naturaleza, más bien hay una total separación y distanciamiento de ella. La naturaleza es recurso al servicio del hombre y susceptible de dominación y explotación. No cabe duda de los grandes desarrollos científicos-tecnológicos que produjo esta forma de mirar al mundo, asimismo las consecuencias nefastas de los mismos hoy se encuentran en magnitud proporcional a dichos avances. Esta cosmovisión poco a poco fue entretejiéndose en la cotidianeidad social. La naturaleza se convirtió en objeto de análisis y explotación ilimitada, la creación progresiva de un mercado y un consumidor hoy consumido. El consumo exacerbado; la explotación de la tierra y de los recursos naturales desmedidamente; "(...) el crecimiento tecnológico, económico e institucional (...) no diferenciado, es hoy la causa de los desastres ecológicos, de la difundida conducta criminal de grandes sociedades anónimas, de la disgregación social (...) (Capra, 1992, p. 213). Este paradigma dualista "reduce" la complejidad a lo uno o lo otro, fragmenta los conocimientos, oculta lo creativo, lo inesperado, la novedad, descarta lo que no puede ser cuantificado (Morin, 2001), desconoce la naturaleza sistémica de la trama social.

Dicha cultura favorece la fragmentación en detrimento de la necesaria integración. Del mismo modo en la misma prevalece:

(...) el análisis sobre la síntesis, el conocimiento racional sobre la sabiduría intuitiva, la ciencia sobre la religión, la competencia sobre la cooperación, la expansión sobre la conservación y así sucesivamente. Este desarrollo parcial ha alcanzado ya un punto alarmante, ha llegado a constituir una crisis que presenta dimensiones sociales, ecológicas, morales y espirituales (Capra, 2006, p. 84).

Desde la cultura matríztica-biocéntrica, se reconoce hombre y naturaleza como hebras de la trama vital afectadas y afectando el entorno natural-ecológico del que formamos parte. En este contexto, la naturaleza deja de ser objeto de dominio y manipulación para ser uno con cualquier forma de vida. Esta concepción forja una conciencia participativa (Berman, 2001), colaborativa que permite a las personas recuperar la conciencia de totalidad de la que son parte. En esta concepción la potencia de la semilla es la clave en la que se inscribe esa capacidad de despliegue que existe en la naturaleza, que es parte del hombre y a la inversa. Sistemas y entornos son categorías recursivas para la naturaleza y cualquiera de sus creaciones, minerales, vegetales, animales y ser humano.

\section{A.3 Metáforas dominantes y arquitectura organizativa}

En el marco de la perspectiva patriarcal-antropocéntrica el mundo es visualizado como una máquina, donde la vida y su propósito se diluyen en la marcha de sus propios engranajes. La 
mecánica newtoniana se encargó de perfeccionar este modelo. Todas las disciplinas apoyaron sus desarrollos en la teoría matemática de Isaac Newton, en la filosofía cartesiana y en la metodología científica preconizada por Francis Bacon. La ciencia acuñó una perspectiva reduccionista de la realidad que prevaleció durante los siglos XVII, XVIII y XIX y trajo aparejada una visión mecanizada del universo. Los principios de la mecánica newtoniana y el racionalismo fueron tomados y aplicados en las ciencias humanas, ciencias sociales, la sociedad misma. El dominio del hombre sobre la naturaleza constituye el eje central del desarrollo científico y tecnológico. En este contexto, el hombre moderno vive acorazado y enajenado en el sí mismo y con respecto a los otros (Reich, 1927). Muchos siglos después continuamos cohabitando esta crítica fragmentación en nuestra convivencia. Orientados por la metáfora de la pirámide; la violencia, el malestar y la descalificación suelen ser modos operativos de funcionar cotidianamente en las relaciones humanas.

En las culturas organizacionales centradas en una visión patriarcal-antropocéntrica, existe una arquitectura basada en la geometría euclidiana; estudio clásico del espacio, donde las personas siguiendo las categorías de su Euclides, constituyen elementos que deben encajar en espacios métricos y normados. La arquitectura organizativa se define de este modo como una estructura fija preestablecida, empobrecida y limitada. En dicha estructura se erige la jerarquía, la verticalidad y el control, configurando un espacio relacional basado en la obediencia que inhibe la capacidad de expresar nuestro potencial creativo.

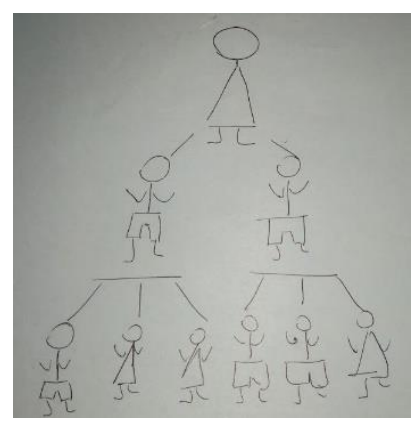

Ilustración 1 dibujo piramidal

Esta cosmovisión del universo mecánico, representado por las punzantes agujas del reloj y los engranajes, Llamazares (2013) se encuentra en una profunda revisión a partir de una mirada centrada en la vida, como punto de partida de todas las cosas.

Desde la configuración matríztica-biocéntrica, se percibe una visión circular-reticular que busca transformar los modelos lineales, piramidales. El mundo se concibe como un sistema orgánico-viviente. La red, las redes de redes y la trama constituyen las metáforas dominantes sustentadas en la geometría sagrada que refleja la vida. Dichas redes no son meros entramados, constituyen articulaciones complejas de la trama vital gestadas en el reconocimiento y el valor de lo uno-único-totalidad.

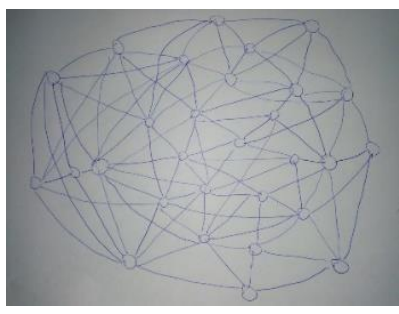

Ilustración 2 RED 1

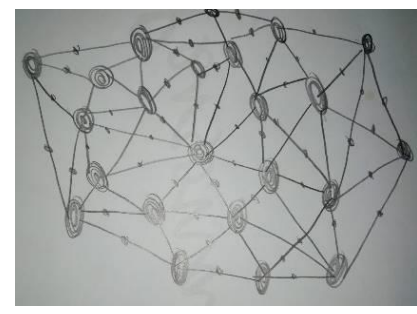

Ilustración 3 RED 2

Volumen, armonía, especularidad y simetría son otras de las notas fundamentales de esta geometría. La arquitectura organizativa se erige a modo de mandala humano, posibilitador de la coevolución y la convivencia pacífica integradora de la diferencia. El círculo y la esfera constituyen imágenes-metáforas de esta red organizativa. El círculo según Cavalcante "Es una representación geométrica infinita donde no hay comienzo ni fin, sólo cambios (Cavalcante, 2008, p.103)". En el círculo hay paridad, equidad, no hay lugares de superioridad por sobre otros, hay una equiparación de todas las personas en un mismo nivel. 


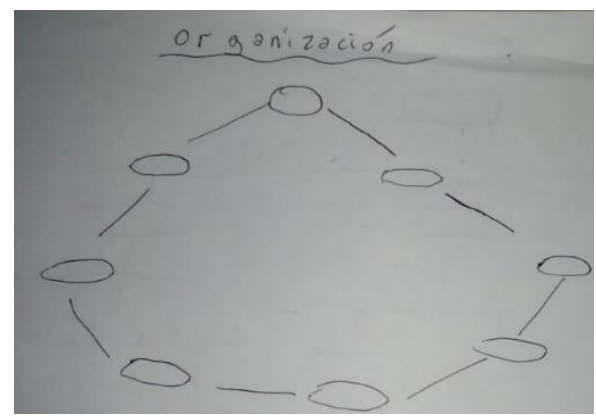

Ilustración 2 dibujo en circulo

Se trata de una geometría no lineal y compleja que en orden a un patrón (Capra, 2006) muestra la arquitectura irregular y fractal (Mandelbrot, 2013) y curvilínea (Koch, como se cita en Jamarillo y Esteban, 2006) de la trama de la vida.

\section{B. Ética}

\section{B.1 Percepción del otro}

Desde la cultura patriarcal-antropocéntrica la ajenidad que se percibe ante el otro, "el otro no soy yo" configura al enemigo. Desde la psicología se ha estudiado profusamente la sombra que el yo no puede ver de sí mismo y proyecta en el otro. Ese punto ciego determina el vínculo y de este modo las posibilidades de poder hacer algo con lo que el otro me devuelve y espeja. Ahora bien, desde esta configuración, donde el otro nada tiene que ver conmigo, porque no se ajusta a mis expectativas predeterminadas y fijas, las posibilidades de establecer un vínculo saludable son bajas o nulas. Al configurar al otro como enemigo, la posibilidad de construir una totalidad colectiva queda invalidada. Esta alternativa funda espacios relacionales infértiles. No hay opción para el encuentro. El yo produce un cerramiento en sus propios esquemas mentales y se sesga ante la novedad. Sedimenta lazos en la negación y anulamiento del otro (Perlo, Costa y de la Riestra, 2009) dificulta la posibilidad coevolutiva (Jantsch, 1980) de la vida e impide el establecimiento de un nosotros. El estancamiento en esta configuración genera ecofactores negativos, ambientes desnutridos en los que se incrementa la tensión y el malestar. Un corrimiento posible de este lugar de desencuentro podría ser habilitado a través de la configuración del adversario, donde la diferencia en lugar de ser combatida y atacada puede ser aceptada. Es la posibilidad de indagar en lo diferente y establecer algún tipo de negociación.

Desde la cultura matríztica-biocéntrica el encuentro humano requiere en primer lugar, un encuentro personal con uno mismo. Esta posibilidad de mirarse hacia adentro alberga la posibilidad de aceptar al ad-versario, ad-verso, otra versión de mí y dar paso a la configuración que reconoce la diferencia y le hace lugar. Disponemos nuestra atención para habilitar un encuentro con la diferencia que nutre nuestra mismidad. Esta configuración es posible cuando las personas asumen su propia responsabilidad en el vínculo. Esta asunción otorga una profundidad al encuentro humano donde el aprendizaje se erige como camino ineludible para la convivencia. Dicho aprendizaje involucra la múltiple articulación entre lo personal, lo colectivo, lo organizacional. Implica asumir una posición ética que nos compromete a estar conscientes y atentos a la relación con nosotros mismos y con el otro. Se abre un espacio para lo creativo que integra el encuentro con la otredad. Se produce allí un lugar de co-creación y expansión de significados; en este sentido el encuentro con el otro constituye una alternativa de abundancia. Se concibe una realidad co-gestada, construida-con, entramada por y entre los participantes implicados. Esta cultura reconoce la totalidad en la que participamos. La apuesta es la hospitalidad del yo (Derrida, 1999) para albergar al otro como legítimo otro, esto es el semejante que lejos de negar la diferencia, la acepta y la celebra.

\section{B.2 Vínculos prevalecientes}

En la cultura patriarcal-antropocéntrica; el otro ajeno y extraño se vuelve una amenaza. Los vínculos centrados en la sospecha ante la diferencia que propone el otro, oscilan entre la intolerancia, el enojo, el miedo, la sumisión, la desconfianza, la descalificación, la exigencia, ira y la violencia. Lo desconocido se vuelve peligroso; por lo cual, la respuesta es la lucha. No hay cabida para lo que ponga en riesgo la estructura fija, no hay posibilidad de vinculación excepto negar esa diferencia para proteger aquello que excede la estructura personal. La competencia, la exigencia y la presión caracterizan estos vínculos, donde quedarse supone un desmedido esfuerzo.

Desde la cultura matríztica-biocéntrica, el encuentro con la diferencia está signado por el respeto. Lo adverso plantea otra versión y gesta la posibilidad del encuentro. Existe cierta inquietud y tensión que lejos de producir enojo genera curiosidad y empatía. El reconocimiento propicia confianza y aprecio. El sostenimiento creativo de la tensión en un tiempo y espacio deviene en 
valoración y calificación. La diferencia es una invitación a generar relaciones colaborativas, donde el otro se diluye como obstáculo y se erige como gran oportunidad. La asunción de la responsabilidad en la calidad del vínculo produce compromiso. De la conciencia de ser parte de una trama indivisa que nos sostiene en un todo fuertemente interconectado, emerge un sentimiento de gratitud por el encuentro. Se trata de un encuentro epifánico (Toro Araneda, 2007), cuyo hilo central de conexión es el amor.

\section{B.3 La concepción en juego del poder}

La cultura patriarcal-antropocéntrica nos ha conducido a un profundo desequilibrio donde el ego fragmentado y desmedido ha quedado confinado a la lucha entre jerarquías. Esto es lo que Llamazares (2013) denomina el "hechizo de poder" en que vivimos a nivel cultural; la autora sugiere que la razón desmedida de la modernidad apela a la ilusión antropocéntrica de "tener" poder y control ilimitado. De este modo el juego de poder que se establece supone la imposición, opresión y superioridad sobre el otro. Se trata aquí de ganar o perder; hay un enemigo al que vencer. A pesar de los profusos estudios de Michel Foucault (1993) que señalaron claramente a través del concepto de "biopoder" la naturaleza reticular del mismo, la percepción fragmentada continúa dividiendo entre seguidores y seguidos, donde la manipulación da lugar al abuso y la sumisión esconde la desresponsabilización en el vínculo.

Desde la cultura matríztica-biocéntrica, el poder no es una fuerza ajena a mí que necesito tomar de los otros en un vínculo de manipulación, opresión y sumisión. En claro contraste el poder es inherente a nuestra naturaleza autopoiética. Por lo tanto, es concebido como una fuerza que tomo de mí e intercambio con los otros en un dar y recibir en reciprocidad. Se trata de un proceso pulsante de asunción y otorgamiento. El poder es flujo e interacción. Es en este sentido que se pone el acento en una construcción relacional del poder alejada del "tener" enraizado en el paradigma positivista y reforzado por el modelo productivista originado en las sociedades capitalistas e industriales. Se trata de una concepción del poder centrada en el "ser y estar" con otros, fundada en una perspectiva sistémica y compleja. La lógica de juego de poder que se establece es "ganarganar". El proceso que se genera es coevolutivo (Janstch, 1980) hay una fuerza común sinérgica, que facilita el encuentro con el otro y posibilita a las personas la cooperación en un proceso creativo y transformativo de sí mismo, del otro y del entorno. A este proceso Maturana y Dávila (2007) han denominado "co-inspiración".

\section{B.4 Modalidades conversacionales}

En el contexto de la cultura patriarcal-antropocéntrica, las modalidades conversacionales se establecen dentro de una estructura que dificulta el encuentro con otro diferente. En este contexto la posibilidad comunicativa se enmarca dentro de lo que Issacs (1999) denominara "debate tosco" (Costa, Perlo y de la Riestra, 2006). En este estilo conversacional están presentes las cuatro patologías que inhiben la posibilidad de pensar y cohabitar juntos. La violencia, abstracción, certeza e idolatría presentes en la conversación constituyen un vínculo tanático productor de la muerte de los significados entre los que conversan. Con el enemigo no es posible construir significado común. Las modalidades conversacionales improductivas, aumentan la fragmentación y debilitan la posibilidad de construir acuerdos con otros. No hay posibilidad para la negociación de significados.

Estos estilos conversacionales convergen con las posturas "críticas" que se alinean con la concepción de la diferencia que supone un enemigo. En este sentido acordamos con Valles cuando expresa: "La perspectiva crítica acentúa los enfoques de la dominación, de la distribución del poder y las desigualdades asociadas; apunta a los efectos del sistema y se adecua al compromiso político (Valles, 1997, p. 56). Este modo conversacional basado en el borramiento del otro, de sus necesidades y su capacidad expresiva impide toda posibilidad de convivencia.

Desde la cultura matríztica-biocéntrica, se promueve el desarrollo y adquisición de habilidades conversacionales que impulsen hacia conversaciones productivas y procesos de diálogo generativo. En una modalidad conversacional productiva están presentes al menos dos prácticas conversacionales básicas: el hablar cuidadoso y la escucha atenta. El hablar cuidadoso implica el respeto por la diferencia y la suspensión de los juicios que requiere tomar conciencia y observar nuestros pensamientos y sentimientos. La escucha supone dos instancias, en primer lugar, escucharnos a nosotros mismos y en segundo, escuchar al otro.

Dentro del campo de las conversaciones productivas podemos describir el diálogo como una modalidad especial de conversación.

La palabra diálogo viene de dos raíces griegas: día y logos, que sugieren significado que fluye a través de. Este sentido de la palabra está en absoluto contraste con lo que normalmente pensamos como "diálogo"- un debate mecanicista e improductivo entre las personas que buscan defender sus puntos de vista unas contra otras. En el diálogo, como utilizamos el término, la gente aprende gradualmente a suspender sus intercambios defensivos y más aún, a sondear dentro de las razones subyacentes de por qué existen esos intercambios (Isaacs, 1999, p.30). 
Las personas que dialogan transforman y co-construyen significados compartidos, colaboran bajo la lógica ganar-ganar. Al respecto Martin Buber (1982), propone al diálogo como un "un modo de intercambio entre los seres humanos donde hay un auténtico volcarse al otro" (Buber, $1982, \mathrm{~s} / \mathrm{p})$.

El diálogo es generativo en tanto brinda a las personas y organizaciones la posibilidad de explorar nuevas alternativas, abrir espacio para la novedad y la creatividad, construir significado compartido, transformar los vínculos y pensar juntos acciones conjuntas.

\section{Epistemología y currículum \\ C.1- Conocimiento}

Desde la perspectiva antropocéntrica-patriarcal, el conocimiento se ciñe al acto pedagógico de transmisión lineal donde un individuo enseña y otro aprende. La transmisión y la acumulación son dos movimientos fundantes de este proceso que Freire (1970) describió magistralmente a través del concepto de "Educación bancaria"

La validación de las hipótesis y la fragmentación del conocimiento en disciplinas desconexas han sido rasgos marcados del modelo citado. La exigencia y rigurosidad metodológica provocaron un conocimiento alejado de la creatividad (Perlo, 2014).

El eje estuvo puesto en el ordenamiento del entorno físico-natural y social estructurando categorías y clasificaciones de los reinos de la naturaleza, las conductas y emociones humanas (Perlo, 2014). De este modo, se fue fragmentando y separando tácitamente el conocimiento de la vida. Se trata de un conocimiento basado en la representación del mundo, su explicación e interpretación. La razón y el lenguaje tienen predominio en este modo de conocer.

En el marco de la cultura matríztica-biocéntrica el acento no está puesto en la díada enseñar y aprender sino en la inseparable dupla conocer y vivir. Varela, Thompson y Rosch (1992) desarrollan el concepto de enacción (lo que se hace emerger), para explicar el acto de conocer. Para los autores el conocimiento es un proceso ontológico donde sujeto y objeto surgen simultáneamente y se determinan el uno al otro. En la acción de observar estamos dando existencia al fenómeno y a la realidad que se observa. Conocer es el producto de una experiencia y elaboración subjetiva. Dice Varela (1990) al respecto:

(...)Proponemos como nombre el término enacción para enfatizar la creciente convicción de que el entendimiento no es la representación de un mundo predado, sino la puesta en escena o la gestación de un mundo sobre la base de la historia y la diversidad de acciones efectivas que un ser puede llevar a cabo (Varela, Thompson y Rosch, 1992, p.73).

A través del concepto de autopoiésis, Maturana y Varela (1998) dejan claro que el ser humano constituye una continua creación y recreación de sí mismo. Cuando el ser humano se reconoce autor-cocreador de la realidad que habita y responsable de que su observación configura lo que conoce, la responsabilidad del conocimiento es compartida y se enfoca en un vínculo de generación creativa en donde la intuición e imaginación son parte del proceso de conocer (Perlo, 2014).

Desde esta perspectiva el conocimiento se encuentra centrado en la vida y conduce al desenvolvimiento pleno del ser humano. En este proceso vital la percepción tiene prioridad ontológica. Conocer implica integrar el sentir (percepción- emoción), el pensar (razón- lenguaje) y el actuar (acción). La sabiduría se encuentra alojada en el cuerpo (Toro Araneda, 2007).

No existe conocimiento por fuera de las personas que puedan ser transmitido y acumulados. Lo que vemos fuera se encuentra en íntima vinculación con nuestra estructura biológica (Maturana, Varela 1998; Weick, 1979), sistema nervioso que decide aquello que conoce en simultaneidad con lo que vive (Damasio, 2011).

\section{C.2- Instrumentos de abordaje de la realidad}

La fuerte impronta del positivismo imprimió en el proceso de conocer una marcada huella en torno a la observación empírica, la medición y la cuantificación.

El método hipotético deductivo, la medición precisa y el cálculo algorítmico constituyeron el sustento básico del pensamiento que moldeó una mirada obsesiva en búsqueda frenética de una ilusoria objetividad.

Desde la cultura patriarcal antropocéntica, la realidad es abordable mediante artefactos culturales (Weick, 1979) que han generado un grave distanciamiento entre el observador y lo observado (Perlo, 2014). Si bien dichos artefactos han permitido grandes avances en ámbitos específicos de la deriva humana, su uso exacerbado ha ido descentrando al ser humano de sí 
mismo, de su semejante y de su natural capacidad creativa. En los laboratorios descontextualizados de la vida, subsumidos detrás de la lente del microscopio, los tubos de ensayo encapsularon la imaginación humana. La realidad, inasible para el ojo humano, emergió claramente, aunque diseccionada (parte). El conocer prescindiendo del desarrollo del ser se hizo hábito y encontró sospechoso éxito en el desarrollo socioeconómico de las sociedades modernas.

Desde la cultura matríztica-biocéntrica estamos inmersos en la realidad desde el propio deseo y proceso de vivir; a través del cuerpo, los sentidos, revalorizando la base biológica instintiva del ser humano (Toro Araneda, 2007). La vivencia constituye el vehículo natural e ineludiblemente integrado al conocer de todos los seres vivos (Maturana, Varela, 1984). El holograma, el caleidoscopio nos acercan luminosas imágenes de inmersión en la realidad. Ya no es necesario abordarla, estamos allí dentro en tanto subtotalidad de una totalidad compleja (Böhm, 2008). Observador y observado se funden en una ecología de saberes donde la fuente de conocimiento es la vida misma.

\section{C.3-Inteligencia}

Desde la perspectiva patriarcal-antropocéntrica, la inteligencia se centró en el hemisferio cerebral izquierdo, racional, analítico, lógico-deductivo. Se enfocó en un tipo de inteligencia instrumental, funcional a la inserción cultural y socioeconómica del contexto. Sustentada en una gran variedad de test, esta posición no sólo provocó una fuerte separación entre las personas discriminando entre los más inteligentes y los menos inteligentes, de acuerdo a los rangos de coeficiente intelectual que resultan de tales pruebas; sino que más drásticamente aún, separó al ser humano de su diversa y potente inteligencia. El no reconocimiento de habilidades y saberes que no resultaban "exitosos" para el intercambio económico dentro del sistema, condujo a un irreparable reduccionismo de las capacidades en la vida de las personas. De este modo se concibió una inteligencia disyuntora (Morín, 2001) que ignoró lo emoción (e-motion=movimiento) en tanto motor del conocimiento.

Desde la perspectiva matríztica-biocéntrica, en palabras de Francisco Varela (1992) "es inteligente aquel que es capaz de vivir en un mundo compartido" (Varela, 1992, s/p). Según Toro Araneda se trata de la capacidad de establecer conexiones con la vida y relacionar la identidad personal con la del universo" (Toro Araneda, 2007, p. 32). Esta concepción, parte de la consideración de la persona como totalidad integrada originariamente entre sus tres cerebros, reptiliano (instintos), límbico (emociones), y cortical (razón), (MacLean, 1990). Esta perspectiva supone la existencia de inteligencias múltiples (Gardner, 1998), que no se restringen al cerebro cortical. Gardner reconoce ocho tipos de inteligencias: lingüística, lógico-matemática, espacial, musical, corporal cenestésica, intrapersonal, interpersonal, naturalista. El aporte de este autor ha sido decisivo para dejar atrás una perspectiva sesgada y constreñida de la inteligencia.

Se busca integrar afectividad y razón, destacando el valor de los instintos para el desarrollo de la inteligencia. La inteligencia refiere a un saber ser y estar con otros que no descuida el contexto (entorno), pero no es dependiente de él. Esta inteligencia se desarrolla a partir de pautas internas de cada persona para vivir ya que en tanto unidades autopoiéticas (Maturana, Varela, 1984) las personas cuentan con la capacidad de autogenerarse y especificarse a sí mismas en interdependencia con el entorno.

\section{C.4- Estrategias metodológicas}

Las concepciones arraigadas en el proceso educativo enmarcado en la cultura patriarcalantropocéntrica establecen un proceso de adoctrinamiento. En este contexto, no se produce un intercambio sino un vínculo de única dirección entre alguien que concede un saber y alguien que pasivamente lo recepciona. Esta linealidad supone la administración de ciertos recursos de parte del portador del saber que se impondrán a través de exigencia, control, esfuerzo y refuerzo, premios y castigos a aquellos que recibirán el mismo. El sistema educativo ha organizado el tiempo y el espacio escolar para forjar cuerpos exteriormente enyesados e interiormente dóciles. La disposición espacial en las aulas, de banco en línea de montaje desvanecieron la presencia plena de sí misma y del otro. Este estilo educativo ha producido un gradual distanciamiento y desconexión en el proceso de enseñar-aprender; un desencantamiento del saber. Los alumnos confinados a la quietud de receptores han ido limitando la libre expresión de sus propios deseos, necesidades naturales y el impulso instintivo vital. Se valoriza el conocimiento jerarquizado (generalmente por el mercado) organizado en disciplinas. Se sobrestima la evaluación por sobre el aprendizaje. El alumno queda a la espera de ser habilitado por un otro para ser y aprender; no hay construcción común del conocimiento, existe unidireccionalidad: el que "sabe" "califica" al que aprende sin "cualificarlo"; uno da y otro recibe acumulando información. La docilidad vuelve más hábil a quién aprende sobre las respuestas que se espera de él. De este modo el cuerpo va perdiendo su movilidad natural y orgánica y se vuelve presa de la manipulación; así va tomado forma, actitud y aptitud para responder y obedecer (Focault, 1993). Los privilegios y recompensas se constituyen en poderosas 
herramientas para la represión y el control en el contexto educativo antropocéntrico orientado al disciplinamiento y la normalización; esto equivale al sometimiento, docilidad y pérdida de la autonomía creativa que todo ser humano tiene en tanto unidad autopoiética (Maturana y Varela, 2003).

De la perspectiva matríztico-biocéntrico, no hay estrategia sino encuentro humano. Se trata de una construcción interdependiente entre "quien enseña y quien aprende", en tanto roles asignados en un contexto institucional. Ontológicamente hablando no existe una división taxativa que separe el enseñar y el aprender. Asimismo, la asunción del rol de enseñar supone una tarea de facilitación y no de instrucción. Esto es ofrecer una forma que posibilite que aquello que las personas deseen, acontezca. Se trata de escuchar y fortalecer recursos y procesos en cada persona o grupo para su aprendizaje y coevolución; guiar, "Explicitar y apoyar al cambio autoorganizado" (Rough, 2002). El facilitador se configura, así como un guardián de los procesos autoregulados (Morin y Pakman, 1994), un artesano de contextos (Fuks, 2009). De este modo se impulsa la autonomía en interdependencia con otros. Se trabaja sobre un vacío, que no implica ausencia, sino fertilidad, simiente de la novedad que requerirá de la búsqueda, el asombro, reconocer, reconocerse y reconocer al otro en el proceso de conocimiento, que será en cualquier caso construcción en colaboración. De este modo el saber emerge en un proceso fecundo de co-inspiración con el otro y no de determinación. La imaginación y la creatividad constituyen los principales nutrientes de este proceso. El eje de organización del currículum es la vida se desarrollado:

En el siguiente cuadro presentamos las categorías y subcategorías que hasta aquí hemos

Cuadro: Diálogo entre la Cultura patriarcal- antropocéntrica y la cultura una cultura matríztica-biocéntrica en los contextos organizativos ${ }^{2}$

\begin{tabular}{|c|c|c|}
\hline DIMENSIONES/CULTURA & $\begin{array}{c}\text { PATRIARCAL- } \\
\text { ANTROPOCÉNTRICA }\end{array}$ & MATRIZTICA-BIOCÉNTRICA \\
\hline A-ONTOLOGÍA & Mirada mecanicista & Mirada compleja \\
\hline A.1-Ser y Realidad & $\begin{array}{c}\text { El ser humano se encuentra en } \\
\text { el centro y cúspide de la } \\
\text { pirámide. } \\
\text { Realidad dada, determinada, } \\
\text { objetiva e inteligible a los seres } \\
\text { humanos. Existe un adentro y } \\
\text { afuera. }\end{array}$ & $\begin{array}{c}\text { La vida tiene primacía por } \\
\text { sobre todos los seres vivos. } \\
\text { Realidad construida, } \\
\text { multidimensional, inasible, } \\
\text { parcialmente inteligible, a } \\
\text { alguna de sus subtotalidades } \\
\text { cognoscentes. } \\
\text { Ser inmerso en la realidad }\end{array}$ \\
\hline A.2-Relación Ser- Naturaleza & $\begin{array}{c}\text { El ser humano escindido de la } \\
\text { naturaleza. } \\
\text { Naturaleza es un recurso que } \\
\text { está al servicio del hombre para } \\
\text { ser dominada, explotada, y } \\
\text { transformada. } \\
\text { Dualismo. }\end{array}$ & $\begin{array}{c}\text { La vida es el principio } \\
\text { organizador del universo. } \\
\text { Interdependencia de los seres } \\
\text { vivos. Integración }\end{array}$ \\
\hline $\begin{array}{l}\text { A.3-Metáforas Dominantes y } \\
\text { arquitectura organizativa }\end{array}$ & $\begin{array}{l}\text { Mundo-máquina- pirámide } \\
\text { Estructura vertical basada. } \\
\text { Orden establecido y fijo, } \\
\text { jerarquía, control y obediencia. } \\
\text { Geometría Euclidiana }\end{array}$ & $\begin{array}{l}\text { Mundo-sistema orgánico- } \\
\text { viviente. Red. Estructura } \\
\text { reticular, rizomática, vertical y } \\
\text { horizontal. Geometría sagrada, } \\
\text { fractal, irregular, simetría, } \\
\text { especularidad, armonía }\end{array}$ \\
\hline \multicolumn{3}{|l|}{ B-ÊTICA } \\
\hline $\begin{array}{l}\text { B.1-Percepción y configuración } \\
\text { del otro }\end{array}$ & $\begin{array}{c}\text { El enemigo, negación de la } \\
\text { otredad }\end{array}$ & $\begin{array}{l}\text { El adversario, aceptación de la } \\
\text { otredad } \\
\text { El semejante, celebración de la } \\
\text { otredad }\end{array}$ \\
\hline B.2-Vínculos prevalecientes & $\begin{array}{c}\text { Ego amenazado } \\
\text { Sospecha, Enojo, miedo, } \\
\text { sumisión, desconfianza, } \\
\text { descalificación, competencia, } \\
\text { presión, esfuerzo desmedido, ira, } \\
\text { violencia. }\end{array}$ & $\begin{array}{l}\text { Respeto, curiosidad, tensión } \\
\text { creativa, reconocimiento, } \\
\text { empatía, confianza, aprecio, } \\
\text { valoración, calificación, } \\
\text { compromiso, colaboración, } \\
\text { gratitud, amor. }\end{array}$ \\
\hline
\end{tabular}

${ }^{2}$ La elaboración conceptual de este cuadro se realizó con la colaboración de la Lic.Carolina Cardú 


\begin{tabular}{|c|c|c|}
\hline & & \\
\hline $\begin{array}{l}\text { B.3- La concepción en juego del } \\
\text { poder }\end{array}$ & $\begin{array}{l}\text { Opresión, manipulación, lucha, } \\
\text { fragmentación. } \\
\text { Tener- Ganar o perder- Vencer } \\
\text { Superioridad-Liderazgo } \\
\text { Abuso y des-responsabilización }\end{array}$ & $\begin{array}{l}\text { Naturaleza autopoiética., } \\
\text { Fuerza personal } \\
\text { Intercambio, dar y recibir, } \\
\text { reciprocidad, proceso pulsante, } \\
\text { Relacional, asunción y } \\
\text { otorgamiento, flujo e } \\
\text { interacción. } \\
\text { Ser y estar "ganar-ganar". } \\
\text { Coevolutivo, co-operación, co- } \\
\text { inspiración. }\end{array}$ \\
\hline $\begin{array}{l}\text { B.4- Modalidades } \\
\text { Conversacionales }\end{array}$ & $\begin{array}{c}\text { Debate tosco. } \\
\text { Modalidades conversacionales } \\
\text { improductivas } \\
\text { Patologías del pensamiento } \\
\text { colectivo: violencia, abstracción, } \\
\text { certeza e idolatría. } \\
\text { Posturas críticas. Muerte de } \\
\text { significados }\end{array}$ & $\begin{array}{c}\text { Conversaciones productivas, } \\
\text { hablar cuidadoso, escucha } \\
\text { atenta. } \\
\text { Suspensión de los juicios, flujo } \\
\text { de significados } \\
\text { Diálogo generativo. } \\
\text { Construcción de significados } \\
\text { compartidos. }\end{array}$ \\
\hline \multicolumn{3}{|l|}{ C- EPISTEMOLOGIA } \\
\hline C.1-Conocimiento & $\begin{array}{c}\text { Acumulación y transmisión de } \\
\text { información } \\
\text { Predominio de la razón y del } \\
\text { lenguaje } \\
\text { Representación, explicación e } \\
\text { interpretación del mundo } \\
\text { Enseñar y aprender. }\end{array}$ & $\begin{array}{c}\text { Proceso vital, biológico y } \\
\text { cultural (en lo humano) } \\
\text { Prioridad ontológica de la } \\
\text { percepción } \\
\text { Conocer y vivir } \\
\text { Enacción } \\
\text { Integración del sentir } \\
\text { (percepción- emoción), pensar } \\
\text { (razón) y actuar (acción) }\end{array}$ \\
\hline $\begin{array}{l}\text { C.2-Instrumentos de abordaje de } \\
\text { la realidad }\end{array}$ & $\begin{array}{c}\text { Cuantificación } \\
\text { Lente } \\
\text { Objetividad } \\
\text { Experimento } \\
\text { De las partes al todo }\end{array}$ & $\begin{array}{c}\text { Vivencia } \\
\text { Holograma } \\
\text { Caleidoscopio } \\
\text { De las subtotalidades a la } \\
\text { totalidad } \\
\text { Complejidad. Ecología de } \\
\text { saberes } \\
\end{array}$ \\
\hline C.3-Inteligencia & $\begin{array}{c}\text { Cortical- racional } \\
\text { Lógica-matemática } \\
\text { Coeficiente intelectual } \\
\text { Dependiente del contexto } \\
\text { socioeconómico }\end{array}$ & $\begin{array}{c}\text { Instintiva, afectiva y cortical } \\
\text { Saber ser y estar con otros } \\
\text { Inteligencias Múltiples } \\
\text { Interdependiente con el } \\
\text { entorno. }\end{array}$ \\
\hline C.4-Estrategias metodológicas & $\begin{array}{l}\text { Portador y receptor del saber } \\
\text { Administración de recursos } \\
\text { Exigencia y Control } \\
\text { Esfuerzo-refuerzo } \\
\text { Represión -Premios y castigos- } \\
\text { Curriculum disciplinar }\end{array}$ & $\begin{array}{c}\text { Encuentro humano } \\
\text { Facilitación } \\
\text { Autonomía, interdependencia. } \\
\text { Autoregulación } \\
\text { Vacío fértil } \\
\text { Asombro, Búsqueda, Re- } \\
\text { conocer y reconocernos. } \\
\text { Imaginación, creatividad. } \\
\text { Currículum basado en la vida }\end{array}$ \\
\hline
\end{tabular}




\section{Reflexiones finales}

En su libro el Cáliz y la Espada Riane Eisler (1990) expresa:

¿Por qué nos acosamos y perseguimos unos a otros? ¿Por qué nuestro mundo está tan lleno de una infante inhumanidad del hombre con el hombre y la mujer? ¿Cómo pueden los seres humanos ser brutales con su propia especie? ¿Qué es lo que en forma crónica nos inclina hacia la crueldad antes que a la bondad, hacia la guerra antes que a la paz y hacia la destrucción que a la realización (Eisler, 1990, p. 11)

En este trabajo hemos buscado revisar los orígenes de nuestra percepción del mundo para vislumbrar el tránsito que hoy nos toca recorrer. Como ya lo mencionamos en otros trabajos (Perlo, 2014) la perspectiva dialógica adoptada en nuestras investigaciones nos ha permitido entablar una conversación fértil entre la coyuntura actual y aquello que vislumbramos como un futuro posible y deseable.

El maltrato y la violencia cotidiana que hoy caracteriza a las sociedades humanas encuentra en las organizaciones educativas y productivas un peligroso y pernicioso caldo de cultivo que reproduce y perpetúa los paradigmas hegemónicos vigentes. La cultura patriarcal-antropocéntrica que aún anida en nuestras organizaciones desfortalece y daña la trama de la vida. Esta es la historia vigente de un

desencantamiento del mundo, (Berman, 2001) de la educación y de las organizaciones por parte de las personas que no cuentan con una conciencia participativa (Berman, 2001).

En esta coyuntura histórica necesitamos un decisivo y urgente viraje hacia el cuidado de la vida y son las organizaciones todas, pero muy especialmente las educativas, un punto fértil de apalancamiento (Senge, 1990) para dicho cambio.

Nuevamente en palabras de Eisler (1990):

De todos los organismos vivos en este planeta, solo nosotros podemos plantar y cosechar los campos, escribir poesía y componer música, buscar verdad y justicia, enseñarle a un niño a leer y escribir —o incluso a reír y llorar. Debido a nuestra capacidad única para imaginar

nuevas realidades y realizarlas a través de tecnologías cada vez más avanzadas, somos, literalmente, copartícipes de nuestra propia evolución (Eisler, 1990, p.11).

\section{Referencias bibliográficas}

Berman, M. (2001). El Reencantamiento del Mundo. Chile: Cuatro Vientos.

Buber, M. (1982). Do diálogo y do dialógico. Brasil: Editora Perspectiva.

Capra, F. (1992). El punto Crucial: Ciencia, sociedad y cultura naciente. Buenos Aires: Troquel.

Capra, F. (1999). El tao de la física. Málaga: Editorial Sirio.

Capra, F. (2006). La trama de la vida. Barcelona: Anagrama.

Cavalcante, R. (2007). Educação Biocêntrica: um movimento de construção dialógica. Fortaleza: $\mathrm{CDH}$.

Cavalcante, R. (2008). La educación Biocéntrica. Dialogando en el círculo de cultura. [En línea] Revista electrónica Pensamiento Biocéntrico № 10. Pelotas. pp. 95-125. [Fecha de consulta: agosto 2013]

Disponible en: https://vdocuments.site/la-educacion-biocentrica-dialogando-en-el-circulo-decultura.html

Cavalcante, R, et. al. (2004). Educación biocéntrica. Un movimiento de construcción dialógica. Fortaleza: Ediciones CDHa Series of Al Workbooks for Leaders of Change". Lakeshore Publishers, Bedford Heights, $\mathrm{OH}$.

Damasio, A. (2005). En busca de spinoza: Neurobiología de la emoción y de los sentimientos. Barcelona: Crítica.

Damasio, A. (2011). El error de Descartes. Buenos Aires: Paidós.

Dávila Yáñez, X. y Maturana, H. (2007). La gran oportunidad: Fin del liderazgo en el surgimiento de la gerencia co-inspirativa. Entendimiento Matriztico Organizacional. Santiago de Chile: Instituto Matriztico.

Derrida, J. (1999). Sobre la hospitalidad. En: Sur parole. Instantanés philosophiques. Paris, Éditions de l'Aube / France Culture.

Eisler, R. (1990). El cáliz y la espada. En: Nuestra historia, nuestro futuro. Chile: Cuatro Vientos.

Freire, P (1970). Pedagogía del Oprimido. Montevideo: Tierra Nueva.

Foucault, M. (1993). Microfísica del poder. Madrid: Piquera.

Fuks, S. (2009). FSPC: La facilitación sistémica de procesos colectivos. "Artesanía de contextos" focalizada en la promoción de la creatividad y de los procesos participativos en grupos, comunidades y redes. En: Revista IRICE, 20, pp.63-76.

Gardner, H. (1998). Inteligencias múltiples. Barcelona: Paidós. 
Gimbutas, M. y Marler, J. (1991). The civilization of the Goddess: The world of Old Europe (p. 400). San Francisco: Harper San Francisco.

Gimbutas, M. (2014). Diosas y Dioses de la Vieja Europa. Madrid: Siruela.

Isaacs, W. (1999). Dialogue: The Art of Thinking Together. USA: Random House.

Jantsch, E. (1980). The self-organizing universe. Oxford: Pergamon Press. Jamarillo, C. M., y Esteban, P. V. (2006). Enseñanza y aprendizaje de las estructuras matemáticas a partir del modelo de Van Hiele. Revista Educación y pedagogía, 18, pp.109-118.

Leopold, A. (1949). A sand county almanac, and sketches here and there. Oxford: Oxford University Press.

Llamazares, A. M. (2013). Del reloj a la flor de loto: Crisis contemporánea y cambio de paradigmas. Buenos Aires: Del Nuevo Extremo.

Maclean, P. D. (1990). The triune brain in evolution: role in paleocerebral functions. Nueva York: Plenum Press.

Mandelbrot, B. (2013). Fractals and chaos: the Mandelbrot set and beyond. Alemania: Springer Science \& Business Media.

Manes, F. F., y Niro, M. (2014). Usar el cerebro. Argentina: Planeta Argentina.

Maturana, H. (1994). Amor y Juego. Fundamentos olvidados del ser humano. Santiago de Chile: Instituto de Psicoterapia.

Maturana, H., \& Varela, F. (1998). De máquinas y seres vivos. Posadas: Universitaria.

Maturana, H. R., y Bloch, S. (2014). Biología del emocionar y alba emoting: respiración y emoción: bailando juntos. Chile: Editorial Uqbar.

Ministerio de Educación de la Nación (2010). Pensar y hacer educación en contextos de encierro 2. Derechos y sistema penal: la dimensión jurídica de las prácticas educativas en contextos de encierro. Buenos Aires, Argentina.

Morin, E. y Pakman, M. (1994). Introducción al pensamiento complejo. Barcelona: Gedisa.

Morin, E. (2001). La cabeza bien puesta. Repensar la reforma. Reformar el pensamiento. Buenos Aires: Nueva Visión.

Muir, J. (1971). My First Summer in the Sierra. Boston: Harold Wood.

Naess, S. (1985). Platform Principles of the Deep Ecology. En Devall Bill, Sessions George, Deep Ecology, living as if Nature Mattered, Gibbs Smith, Salt Lake City, pp. 65-77.

Perlo, C.; Costa, L.; de la Riestra, M.R. (2006). El diálogo como estrategia para el desarrollo de la mente colectiva en las organizaciones: hacia un modelo de intervención. En: Comunidade e Familia.Sao Pablo: NUFAC- Pontificia Universidade de Sao Pablo. vol.2 n². pp. 11 - 36.

Perlo, C.; Costa, L. y de la Riestra, M.R. (2009). Conflicto y emoción. Tensiones emergentes y nuevas configuraciones de la alteridad. I Congreso Iberoamericano de Psicología en la Transformación de las Organizaciones del Trabajo. RIPOT. Montevideo, Uruguay, 30, 31 de Julio y 1 de agosto.

Perlo, C. (2014). Hacer ciencia en el siglo XXI. Despertar del sueño de la razón. Entre Ríos: La Hendija.

Perlo, C. (2014). Siento, existo y luego... pienso: contribuciones para la construcción del conocimiento científico. Utopía y Praxis Latinoamericana. En: Revista Internacional de Filosofía Iberoamericana y Teoría Social (19) № 65. Abril-junio, pp. 75-90.

Reich, W. (1927). La función del orgasmo. El descubrimiento del orgón Problemas económicosexuales de la energía biológica. España. Paidos.

Robledo, G. y Platon, N. (2000). La República, introducción y notas de Gómez Robledo, A. México DF: Biblioteca Scriptorum Graecorum et Romanorum mexicana-UNAM.

Rough, J. (2002). Society's Breakthrough!: Releasing Essential Wisdom and Virtue in All the People. Indiana: AuthorHouse.

Senge, P. (1990). La quinta disciplina. Granica: Buenos Aires.

Strauss, A. y Corbin, J. (1994). Grounded theory methodology. En: Handbook of qualitative research, 17, pp. 273-85.

Toro Araneda, R. (2007). Biodanza. Santiago de Chile: Cuarto Propio.

Varela, F. (1990). El Fenómeno de la Vida. Santiago de Chile: Editorial Dolmen.

Varela, F. J., Thompson, E., y Rosch, E. (1992). El cuerpo presente: las ciencias cognitivas y la experiencia humana. España: Gedisa.

Varela F. y Maturana, H. (2003). El árbol del conocimiento: las bases biológicas del entendimiento humano. Buenos Aires: LUMEN HUMANITAS.

Valles, M. (1997). Técnicas cualitativas de investigación social. Reflexión metodológica y práctica profesional. Madrid: Síntesis.

Weick, K. E. (1979). The social psychology of organizing (Topics in social psychology series). Columbus, OH: McGraw-Hill Humanities. 